\title{
Investigating the future of the Fuzzy Front End: towards a change of paradigm in the very early design phases?
}

Y. Borgianni ${ }^{\mathrm{a}}$, G. Cascini ${ }^{\mathrm{b}}$ and F. Rotini ${ }^{\mathrm{c} *}$

${ }^{a}$ Faculty of Science and Technology, Free University of Bozen-Bolzano, Piazza

Universitá, 5, 39100 - Bolzano, Italy;

${ }^{b}$ Dipartimento di Meccanica, Politecnico di Milano, via La Masa, 1, 20156 - Milano, Italy;

${ }^{c}$ Dipartimento di Ingegneria Industriale, via di S. Marta, 3, 50139 - Firenze, Italy.

*Dipartimento di Ingegneria Industriale, via di S. Marta, 3, 50139 - Firenze, Italy, Email: federico.rotini@ unifi.it, Phone: +39 055 2758745, Mobile Phone: +39 329 17225832, Skype: federico.rotini. 


\title{
Investigating the future of the Fuzzy Front End: towards a change of paradigm in the very early design phases?
}

\author{
Many scholars argue that very early design phases are not supported adequately \\ in many respects, although they are at the cornerstone of successful new product \\ development. Difficulties in developing appropriate methods emerge because of \\ the need to account for uncertainties and ambiguities that feature the Fuzzy Front \\ End. This is likely the reason behind the limited industrial adoption of existing \\ design methods, especially those that are oriented to support Product Planning. In \\ this context, the thrust of the paper is the attempt to identify key activities and \\ functions featuring Product Planning. The study entrusts figures about the \\ foreseeable growth of the intensity of research displayed by classes of methods \\ supporting different functions in Product Planning. As the data, emerging from \\ the application of S-curves, indicate no preferential direction in the medium term, \\ other phenomena are monitored that might overturn the conventional systematic \\ course of action to design in the early stages. The "trial-and-error" learning \\ approach characterizing agile strategies can be seen as a partial answer to the \\ expected demise of research about Product Planning. Beyond these conclusions, \\ the paper includes a frame of reference that classifies Product Planning methods \\ (adequately reviewed) beyond the classical distinction between responsive and \\ proactive approaches.
}

Keywords: Early Design Phases; Fuzzy Front End; Product Planning; S-Curves; Agile Product Development.

\section{Introduction}

As engineering design can be considered quintessentially multidisciplinary because of the interaction with knowledge from multiple domains, some phases of New Product Development (NPD) cycles feature this characteristic even more markedly. According to the acknowledged distinction of engineering design activities, the Fuzzy Front End (FFE) is responsible for the acquisition and preliminary transformation of market inputs, usually in terms of human needs or customer requirements, into a product development project. Many sources from design, e.g. (Tzortzopoulos et al., 
2006; Achiche et al., 2013), and management, e.g. (Dewulf, 2013), provide details about the scopes of the FFE. FFE's constituent phases according to Pahl et al.'s (2007) model, i.e. Product Planning (PP) or task clarification (Bacciotti et al., 2016a; Duarte et al., 2017) and Conceptual Design, are not devoted to define technical structures yet, consistently with the definition of the FFE. They still make use of abstract and not welldefined design objectives - the term "fuzzy" originates from the ambiguity connected with early design phases. Recent research supports the thought that the connection of these phases with non-engineering disciplines contributes to uncertainty, complexity and ambiguity (Ryeong Kim, 2017).

The proximity to non-technical fields, hence the multidisciplinary nature, is even more remarkable for PP due to its objectives (De Lessio et al., 2017). It fundamentally consists in the identification of consumers' needs and the consequent definition of new product characteristics capable of fulfilling customers' and/or users' expectations. This outcome constitutes therefore the product idea the company will concentrate design efforts and available resources on, which is responsible for the criticality of PP within the whole design cycle. The acceptation of the term is not univocal and shared across academicians, as well as the borders between different NPD phases are blurred (Duarte et al., 2017). The authors clarify the meaning of "Product Planning" used in the paper as the complex of creative design and ideation activities that define, in the very early design stages, the main product features in terms of the benefits (practical, technical, affective, emotional or hedonistic) that should be delivered.

In many cases and markedly in Small and Medium Enterprises (SMEs), firms entrust PP to the intuition and the experience of few decision makers despite its relevance. In larger companies, the task is commonly supported by conjoint activities that often involve teams constituted by marketing and technical experts (Bacciotti et al., 
2016a). Marketing professionals usually perform a preliminary benchmark analysis and examine the needs expressed by consumers. Designers investigate the most promising and technically feasible product features to fulfil end users' needs. In this typical approach to PP, the predominance of a market mind-set or a technical logic can represent a distinguishing trait. If the former plays a major role, PP strategies result more customer-oriented and market-pull techniques are likely introduced to perform the task accurately. When customer opinions or inputs are employed as the alpha and omega of design decisions, product development approaches are commonly catalogued as responsive. Conversely, when greater importance is attributed to engineering criteria, the innovation process results technology-push and proactive methods tend to replace market insights with the vision of designers or multidisciplinary NPD teams.

However, despite the existence of many methods that fit both responsive and proactive strategies (Bacciotti et al., 2013), the adoption of structured PP techniques is still limited. Graner and Mißler-Behr (2012) analyse the literature on the adoption of design methodologies in industry and, by observing outcomes about the most diffused tools, a small number of them support PP. Bacciotti et al. (2016a) reinforce these findings by investigating a sample of firms with a specific focus on PP. On the one hand, PP methods suffer from typical problems concerning the relationship between academia and industry, such as poor interaction (Blessing, 2003), misalignment of objectives (Stempfle and Badke-Schaub, 2002) and limited trust (Bruneel et al., 2010). On the other hand, the disregard of literature methods for NPD takes place despite claimed advantages in using systematic instruments (Pahl et al., 2007) and can be attributed to a large number of factors (López-Mesa and Bylund, 2011, Fiorineschi et al., 2018); therefore, specific issues to be prioritized have not emerged. 
As previous literature has not identified a specific reason for the current disregard of PP methods, the present paper attempts to identify the key in the capability of overcoming the above complexity and uncertainties by identifying critical activities and functions in PP. As PP methods have specific foci and do not support the whole design phase (see Section 4), it is supposed that these peculiarities will emerge in the long term. In other terms, it is expected that methods supporting key functions will display greater intensity of research for a longer period than those addressed to less relevant activities. The objective of the paper is to identify the existence of this condition, which could also represent a compass for scholars interested in the field, by means of a bibliographic analysis and the subsequent application of S-curves. The approach to the fulfilment of this objective is described in the next section, together with the corresponding organization of the paper.

\section{General research approach and structure of the content}

The first step of the followed approach consisted in collecting methods for supporting PP activities; thus, a deep analysis was performed of the contributions available in literature. Moreover, an original classification framework was defined to cluster the identified methods, taking into account their relationships with PP activities and functions. Section 3 describes the defined classification criteria and resulting classes (hereinafter clusters), while Section 4 presents an overview of PP methods based on the categorization criteria.

Subsequently, the information about each identified cluster was used to perform a maturity assessment analysis. The latter aimed to verify the existence of meaningful potential margins, in terms of research efforts, for improving the identified methodological approaches. Such an investigation was carried out through a specific approach, which is described in Section 4 together with the main outcomes achieved. 
The trends highlighted through the maturity assessment analysis brought no evidence about clusters with considerable growth margins in terms of research intensity. Therefore, the authors strived to identify causes of this deadlock situation with a closer reference to emerging design approaches in industry and the possibility that the classical product development paradigm could be overturned. To this respect, the diffusion of agile models (as a possible turning point) in the FFE has been investigated with an akin maturity assessment analysis. Activities and outcomes concerning this step are presented in Section 6.

Eventually, through a deductive approach, the achieved results have been revisited in a comprehensive way to highlight the main findings of the study. Section 7 reports and discusses these outcomes together with the main limitations and future work.

\section{A new classification of Product Planning methods based on functions and activities}

The key to achieve organizational goals is to be more effective and efficient than competitors in identifying and satisfying the needs of target markets (Narver et al. 2004; Kotler 2007), by developing and delivering products and services that are valued by customers (e.g. Kim and Mauborgne 2005; Atuahene-Gima et al. 2005). To this objective, two main categories of approaches are defined in literature: responsive and proactive methodologies (Narver et al. 2004; Atuahene-Gima et al. 2005), as anticipated in Section 1. While the former aims to unveil customer preferences and use them as fundamental competing factors, the latter focuses on industry exploration to individuate differentiation opportunities.

However, both categories of methodologies seemingly fail to support product 
development appropriately (Tsai et al., 2008, Soukhoroukova et al. 2012). To this respect, further information is provided in a supplemental file. Besides, these classes fail to characterize a plethora of FFE approaches, as better motivated in the followings.

Bacciotti et al. (2016a) identify literature methods specifically developed for PP and individuate a large cluster of hybrid tools, in which customers play very diverse roles. In some cases, they barely replace R\&D teams in ideation activities. Conversely, other examples see consumers as passive test subjects whose reactions are recorded and subsequently exploited. Otherwise said, an increasing number of approaches overturns the original contribution of customers as questionnaire respondents. Customers' role is shaped according to the peculiar objectives designers aim to achieve. In turn, these objectives largely depend on PP's activities, knowledge domains and outcomes organizations concentrate on, master, and/or judge as the most crucial for achieving successful innovation. According to this vision, companies or designers focus on a certain subset of PP dimensions in light of their innovative approach.

(1) The paper identifies these foci, which follow, and, consistently with the objectives declared in previous sections, proposes an original taxonomy graphically illustrated in Figure 1. The acquisition of information and data (technical, market-related) that are specifically acquired for the product development process;

(2) The elaboration and exploitation of such information to establish design priorities;

(3) The consideration of determinants and external conditions that impact on the process regardless of designers' scopes;

(4) The involvement of players and competences, beyond technical apparatuses and devices, which are however less relevant in such a human-oriented process; 
(5) The definition of product specifications in terms of new features benefitting customers or users or unprecedented product profiles delivering value in an original way.

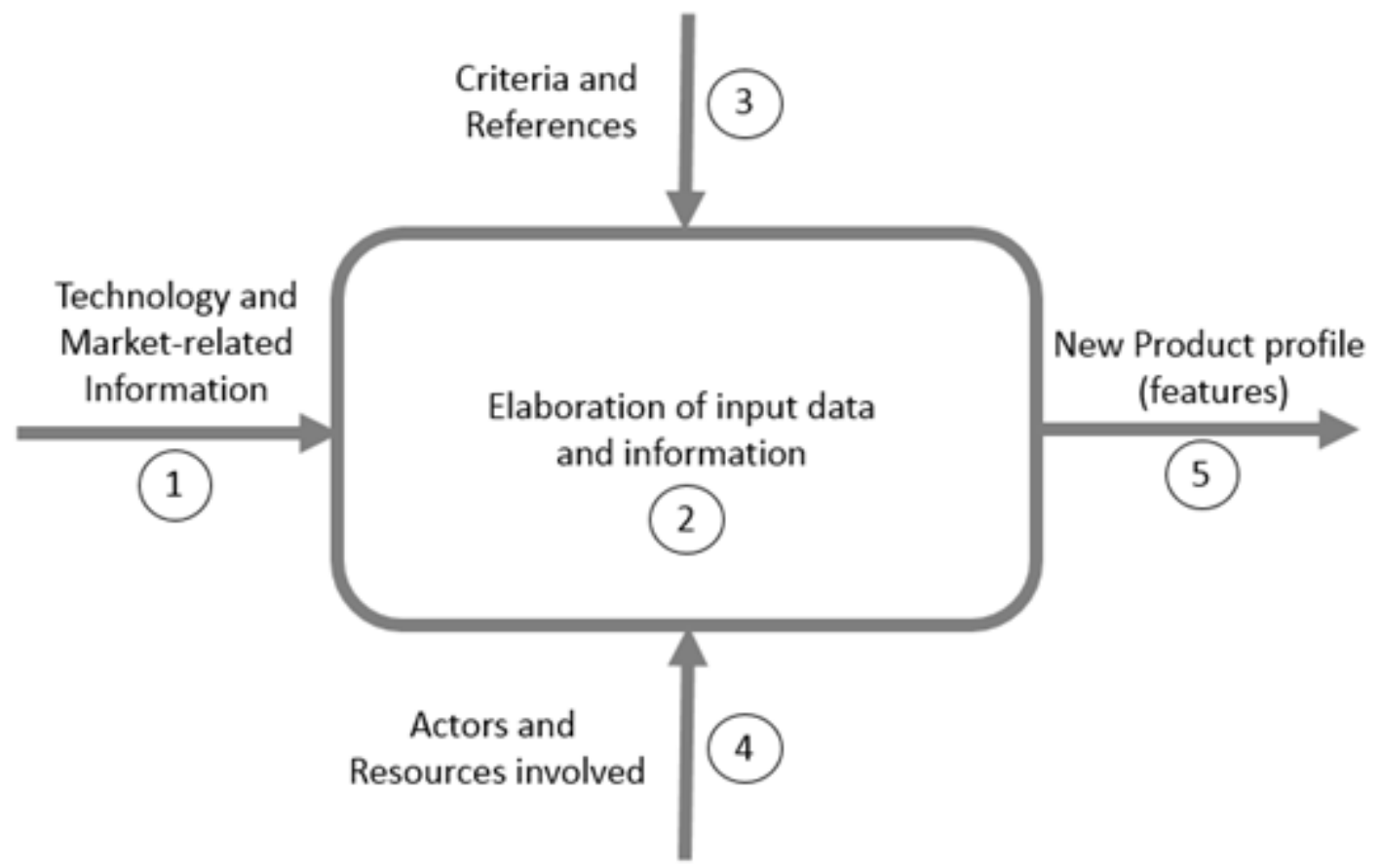

Figure 1: Fundamental flows and activities through which to classify the foci of methods supporting very early design phases.

The new classification allows a distinction of PP approaches with respect to functions instead of customer roles, which, in the new classification scheme, are not defined a priori and can be seen as a "dependent variable".

\section{Foci and functions of Product Planning approaches}

The new classification criteria lead to the determination of five critical PP clusters. The subsections that follow describe approaches to PP that belong to said clusters and hence emphasize pertaining foci. The clusterization has been determined by the authors after 
reviewing the literature and collecting relevant information about approaches and instruments for PP. The numbering of the subsections makes reference to the above numbered list and the circled numbers reported in Figure 1.

\subsection{Focus on market-related information}

This cluster collects design techniques aimed to gather data and information from individual users or from a market sector as a whole to feed the PP process. The techniques may concern the identification of a meaningful sample of respondents, the approaches to elicit latent wishes, the observation of users' behaviour.

In this context, traditional schemas based on the "Voice of the Customer" (VoC) are cases in point of design methodologies that are swivelled on gathered information, hence representative techniques of this cluster. Many scholars (Ramaswamy and Ulrich, 1993; Kärkkäinen and Elfvengren 2002; Chen et al., 2003; Whyte et al. 2003; Agouridas et al. 2008; Liu et al., 2013) claim that bringing the VoC into an organization is the key process of the Front End of product development.

To this respect, practices have replaced the classical way customers are investigated without modifying the basic assumption of designing products based on consumers' responses. This includes studies on human experience, emotions and psychological aspects (Cantamessa et al., 2016). The reliability of this kind of user feedback is enabled by evolving technologies and techniques in human-related studies.

Traditional forms of investigating customers are leveraged in the Lead user method (Von Hippel, 1986; Lilien et al., 2002), which benefits from the accumulated experience of pioneer users (lead users), and in Kansei Engineering (Nagamachi 1995, Schütte et al. 2004), which collects customers' inclinations about alternative ideas. Despite 
methodological drawbacks (Hartono et al. 2012), the latter attracts continuous interest because of an increasing number of fields of application (e.g. Yang 2011; Oztekin et al. 2013) and computer tools implementing its principles (e.g. Zhai et al. 2009; Wang 2011).

Conversely, the analysis of users' emotions is the thrust of many strategies that exploit modern technologies, particularly those based on biometric measures, whose engineering applications have been reviewed by Lohmeyer and Meboldt (2016). Recent applications relevant for product evaluation and exploration of human experience and emotions are described in (Khushaba et al., 2013, Mussgnug et al., 2015, Moon et al., 2017, Mussgnug et al., 2017).

\subsection{Focus on the elaboration of input information}

This cluster comprises methods and techniques that allow the interpretation and the processing of market data and a structured analysis of the market for the new product.

The underlying theory behind Kano model (Kano et al. 1984) constitutes the core of several methodologies extensively applied in different industrial contexts (NilssonWitell and Fundin 2005; Wassenar et al., 2005; Yang 2005). It allows the analysis of the relationship between the offering level of product attributes and the consequent customer satisfaction through the employment of bespoke questionnaires. The relevance, continuous diffusion and outreach of this method is documented in the review paper authored by Witell et al. (2013).

Other data elaboration approaches are still mainly based on customer information, but other criteria and projections are introduced. In particular, evaluations from industrial and technical experts are adequately combined to take product development decisions. 
The contributions by Liberatore and Stylianou (1995) and Matsatsinis and Siskos (1999) support this mechanism in a structured way and keep the focus on specific customer requirements. They suggest a set of statistical tools to match the inputs coming from customer surveys, market and financial analysis, expertise of internal personnel to generate a list of the most beneficial product characteristics.

Further approaches benefit from customer knowledge and other market-related information contextually. For instance, fine-grained studies of market preferences and individuals' traits allow the identification of unexplored niches, as in (Liao et al., 2008).

\subsection{Focus on the boundaries of the design process}

This cluster refers to the external models (regardless of the specific field of application where the new product proposition is expected) that can trigger the generation of the new product profile. Consistently, this subsection discusses the attempts to identify original factors that enable new products to succeed without resorting to customers' information concerning their declared preferences or examined behaviour. Here, the attention on the user or customer shifts from explicable satisfaction dimensions to systems of needs and values, hence the environment and the trends in which product users are immersed.

A circumscribed branch of engineering and management literature directs its attention to well acknowledged structures of human needs and values, including the List of Values (Sakao and Shimomura, 2007), Max-Neef's scheme and Maslow's pyramid (Ericson et al., 2009). The objective is to individuate unprecedented innovation drivers capable of addressing product development. Recent contributions, based on the needfinding paradigm, have strived to develop strategies and techniques that allow individuals to express large numbers of their needs, especially in contexts where direct 
observations are troublesome (Schaffhausen and Kowalewski, 2015). Identified latent needs do not straightforwardly lead to final products and technical solution, so that rapid prototypes and virtual environments in user-centred studies attempt to validate usability of early stage ideas, e.g. (Bulliger et al., 2010; Wooley et al., 2013). However, this rather individualized approach cannot be extended to larger-scale productions. Thus, the aforementioned problem can partially motivate the lack of engineering, design and industrial practices that exploit terms, definitions, conceptualization and assessments of abstract terms, such as human well-being or societal quality-of-life (D’Anna and Cascini, 2016). Indeed, even evolved methodologies that explicitly claim to focus on needs end up introducing customer requirements and functional characteristics in their working procedures (Ericson et al., 2007).

Besides, eco-design strategies (Glavič and Lukman, 2011; Bovea and Pérez-Belis, 2012; Tyl et al. 2014) can be mentioned in the context of operational methods whose objective is the improvement of human life irrespective of customer experience. Some of them are capable of including a system perspective, beyond providing indications for the reduction of the ecological footprint, as in the design of Product-Service Systems (PSS) (Tukker and Tischner, 2006), whose aims and applications have been recently reviewed (Annarelli et al., 2016; Qu et al., 2016).

Eventually, determinants of product development concern not only external factors, but also inherent technological and structural aspects shaping the evolution of artefacts. On the one hand, discontinuities, interactions between stakeholders (Kaplan and Tripsas, 2008) and incremental/radical cycles of performances growth (Suárez and Utterback, 1995) affect the adoption of new technologies at specific points in the evolution of product generations. On the other hand, the structural evolution of designs is influenced by an intertwined network of factors, generally concerning complexity, the number of 
components and the modular/integral architecture of the product (Frey et al., 2007; Borgianni and Matt, 2016).

\subsection{Focus on players and resources that are involved in the design process}

This cluster includes techniques and approaches mostly focused on the organization of human resources for performing the PP process, i.e. for information acquisition and elaboration, idea generation and new product definition.

The proliferation of interconnectivity and interactivity through Internet-based technologies has fostered the introduction of this kind of methods, which support NPD (Klein and Spiegel, 2013) and idea generation particularly (Von Hippel 2005) by involving a growing number of industry players (Büyüközkan and Feyzioğlu, 2004; Füller and Matzler, 2007). A common characteristic of these approaches is the use of distributed knowledge through the interconnection of ideas from a vast number of participants (Toubia 2006). As many variables, ranging from the involved experts and stakeholders to the forms of collaboration, highly affect the quality of design outcomes, many scholars have proposed means to optimize and facilitate the collaborative work (Yoshimura 2012; Pavković et al., 2013). The process of exchanging knowledge and ideas is the pillar of the "open innovation" paradigm, e.g. (Chesbrough and Schwartz, 2006), whose focus is the introduction of new business models. According to open innovation principles, companies are pervaded by inflows of knowledge and ideas that lie outside of organizations. This approach is increasingly embraced by small organizations (Aschehoug and Ringen, 2013). The involvement of a vast number of stakeholders and people with different needs and perspectives is witnessed also outside of the industrial domain, e.g. (de Couvreur and Goossens, 2011). By now, this concept is rooted also in the engineering field; a comparison of 11 approaches open innovation 
underlies is presented in (von Saucken et al., 2015).

\subsection{Focus on new product profiles and features}

This cluster groups methods and techniques whose main thrust is the generation of new product features, irrespective of a careful market analysis. Here, the scope of producing something novel gains priority over the structuration of information that should lead to new concepts according to predefined patterns. This is mirrored by the incessant demand for fundamental innovation, which could be limited by classical flows of market information and consistent product development decisions.

The claim for more radical transformations of existing products provides a great opportunity to apply creative thinking to engineering design and its initial phases in particular. The enhancement of creativity during idea generation is commonly supported through brainstorming, a group activity that foresees the postponement of judging others' ideas and encourages participants to build on each other's ideas (Osborn 1953). Despite the concept is quite old, Brainstorming is extensively used in the industrial practice (Coates et al. 1997; López-Mesa and Bylund, 2011), because it can be easily and intuitively implemented even if it is often introduced in a naïve way, not fully aligned to the original Osborn's recommendations (Matthews 2009).

The popularity of Brainstorming has attracted both praises and criticism. Two main issues have been raised, as described more in detail in the followings: difficulties in managing large sets of ideas (Simonton, 2003; Rietzschel et al., 2006) and argued group capabilities to outperform individual thinking (Rietzschel et al. 2006, Howard et al. 2011).

Also in light of the above limitations, the literature proposes two ways through which to 
boost the effectiveness of the Brainstorming process.

On the one hand, some practices and techniques to support brainstorming sessions have been experimented in several decades and practiced, such as Brainwriting (Aschehoug and Boks, 2011), Mind Maps (Zahedi and Guité, 2013), Bodystorming (Oulasvirta et al. 2003), tailored software applications (Hüsig and Kohn, 2009), giving rise to the socalled "electronic brainstorming" (Aiken et al. 1994).

On the other hand, the stimulation process is supported through different expedients, which include the use of creative stimuli (Chakrabarti 2006; Howard et al. 2011) or the perturbation of the thinking environment, e.g. through humorous means (Wodehouse et al. 2014; Hatcher et al 2016). As more and more stimuli are introduced and imagination is fostered according to a predefined path, the creative ideation process increasingly differs from classical Brainstorming, which is typically carried out without constraining or directing participants' reasoning. As a result, many studies compare classical Brainstorming and the whole family of cognitive ideation methods with analogical ideation techniques (Chulvi et al., 2013; Gero et al 2013), among which TRIZ (Altshuller, 1984) represents an outstanding example, although originally addressed at conceptual design and problem analysis. The literature reveals pros and cons of both categories. Recent contributions, abundantly rooted in TRIZ body of knowledge, support design ideation by submitting users a set stimuli with the aim to minimize overlooked opportunities. A prototype software application (Bacciotti et al., 2016b) claims to stimulate designers through the whole set of potential benefits, in an abstract format, that a product or service can fulfil. With a specific focus on common design patterns, Yilmaz et al. (2016) show a set of 77 combined visual and textual stimuli, namely Design Heuristics, which emerge as a combination of distinct studies conducted with different approaches to highlight commonalities in seeded and repeated successful 
design patterns.

Some approaches to PP based on cognitive abilities show great freedom of thought similarly to Brainstorming, but favour particular directions through which to find new ideas. Lateral thinking (De Bono 1968; 1994) is a well-known technique with a considerable diffusion in industrial contexts (Coates et al. 1997) that, unlike logical "vertical" thinking, pushes individuals to think from different perspectives, overcoming their psychological inertia and generating as many new ideas as possible. Several methods and tools have been tested to support this task, e.g. Mind Maps (e.g. Hüsig and Kohn 2009) and Six Thinking Hats (De Bono 2009; Vernon and Hocking 2016). Other approaches strive to identify the potential user needs and product requirements through a scenario-based analysis. This practice reflects upon most likely product use scenarios and alternative future developments. Scenario-based techniques are already diffused in industrial environments as a means for identifying new products ideas, giving rise to satisfactory results (Suri and Marsh 2000; Flint 2002).

With a more specific business perspective, the attempt to create new frameworks of product features is generally designated as "new value proposition". In this context, the Blue Ocean Strategy (BOS), fine-tuned by Kim and Mauborgne (2005) can be indicated as the most popular reference. Its objective is a radical reconfiguration of the value aspects that consumers have enjoyed so far, also in consideration of different industries. The BOS is capable of supporting innovative NPD initiatives and is observing a growing consensus in industry in the last few years (Lindič et al. 2012), despite some shortcomings in terms of its systematic use (Aspara et al. 2008; Borgianni et al., 2011).

\section{An outlook for Product Planning approaches based on bibliometric data}

The present section aims to investigate expected trends about the relevance of clusters 
(and hence their corresponding functions and activities) in shaping NPD processes. The investigation is performed by taking into account the current and past intensity of research, so that figures about the upcoming years can be extrapolated.

\subsection{Investigation method}

A step-by-step activity has been carried out, as follows.

- Clusters are characterized by a set of key concepts (here expressed in the form of keywords) reflecting their contents. In order to collect these terms, the authors have extracted the original keywords of the papers cited in each cluster ${ }^{1}$, thus forming large groups. Sources that are cited in more than one cluster have been excluded, as they could represent a bias. Keywords appearing in at least two clusters have been highlighted, since they might represent general concepts. Hence, the authors have manually selected (Table 1):

$\bigcirc$ within each identified group and by removing terms appearing in more groups, a sample of specific keywords for each cluster, which should reflect peculiar aspects of PP techniques swivelling on the corresponding focus. Some measures were taken to make the procedure more rigorous; in particular, keywords were eliminated when they concerned broad topics that do not deal with the design field (e.g. computer graphics), general research approaches or methods (e.g. Markov processes), application domains (e.g. automotive supplier industry), distinguishing factors of the publications (e.g. review);

\footnotetext{
${ }^{1}$ Actually, the identification of keywords has been based on the articles included in the first submission of the present paper, which has been subsequently abridged and modified. The authors deem that these changes affect the results to a very limited extent.
} 
- a set of general keywords, within the ones present in more groups, that supposedly characterize the general topic of the present research.

- The keywords were used as terms and labels for individuating sets of potentially relevant scientific documents. It has been assumed that publications relevant to each cluster should make reference to both general and specific keywords. By making this choice, the authors are aware of prioritizing precision over recall. It was therefore assumed that the noise/signal ratio was acceptably similar across the five clusters (a manual selection of the pertinent contributions would have been extremely time-consuming). The Scopus database was used; selected documents forming cluster document sets included at least one general and one specific keyword in the Title, Abstract or Keywords (TAK) list.

- The number of contributions belonging to each cluster document sets is used to estimate the intensity of research and level of interest for each cluster, as a common approach employed in the literature (Efimenko and Khoroshevsky, 2017).

- Changes in bibliometric data over time (years of publication are here considered) are used to observe the evolution of the intensity of research. Based on these figures, S-shaped curves of the cumulated numbers of publications have been interpolated to determine growth potential for research in each cluster. The approach of associating cumulated numbers of documents as logistic curves for forecasting scopes is common in the literature, e.g. (Kumar Patra and Chand, 2005; Daim et al., 2006; Lu and Liu, 2013). The outcomes arisen from different free online applications (Loglet Lab, mycurvefit.com) were consistent. A graphical representation of the emerging curves for each cluster is provided in 
Figure 2, which exploits Loglet Lab. Data about the goodness of fit of the curves

in terms of the $\mathrm{R}^{2}$ coefficient are all above 0.99 .

Table 1: general (second row) and cluster specific keywords (following rows).

\begin{tabular}{|c|c|}
\hline Reference & Relevant Keywords \\
\hline General set & $\begin{array}{l}\text { "conceptual design", "engineering design", "idea generation", "product } \\
\text { development", "product design", "product planning" }\end{array}$ \\
\hline Cluster 1 & $\begin{array}{l}\text { "Affective design", "Augmented reality", "Biosignals", "Consumer } \\
\text { behaviour", "Customer needs", "Customer requirements acquisition and } \\
\text { evaluation", "EEG", "Ergonomics", "Eye tracking", "fMRI", "gaze- } \\
\text { tracking", "House of Quality", "human behaviour in design", "Kansei } \\
\text { Engineering", "lead users", "Neuroimaging", "Reported needs", } \\
\text { "Requirements engineering", "User requirement", "Voice of the } \\
\text { customer" }\end{array}$ \\
\hline Cluster 2 & $\begin{array}{l}\text { "Data analysis", "Data mining", "Importance-satisfaction model", } \\
\text { "Intelligent decision support systems", "Kano method", "Kano's model", } \\
\text { "Kano's theory", "Knowledge extraction" }\end{array}$ \\
\hline Cluster 3 & $\begin{array}{l}\text { "Cleaner production", "dominant design", "eco-ideation", "eco- } \\
\text { innovation", "Environmental requirement", "Ideality", "needfinding", } \\
\text { "Product Service System", "PSS", "Quality of life", "Servitization”, } \\
\text { "Sustainability", "Sustainable development", "Technology life cycle”, }\end{array}$ \\
\hline Cluster 4 & $\begin{array}{l}\text { "Co-design", "Co-development", "Collaborative Design", "Horizontal } \\
\text { user innovation network", "Open design", "Open Innovation", "Virtual } \\
\text { customer integration" }\end{array}$ \\
\hline Cluster 5 & $\begin{array}{l}\text { "Blue Ocean Strategy", "Bodystorming", "brainstorming", } \\
\text { "Brainwriting", "concept generation technique", "Creative design", } \\
\text { "Creative thinking", "Customer value", "Design creativity", "Group } \\
\text { creativity", "humour", "Idea stimulation", "SCAMPER", "Scenario } \\
\text { building", "Six thinking hats", "Value Creation", "Value dimensions", } \\
\text { "Value proposition" }\end{array}$ \\
\hline
\end{tabular}




\section{Number of publications}

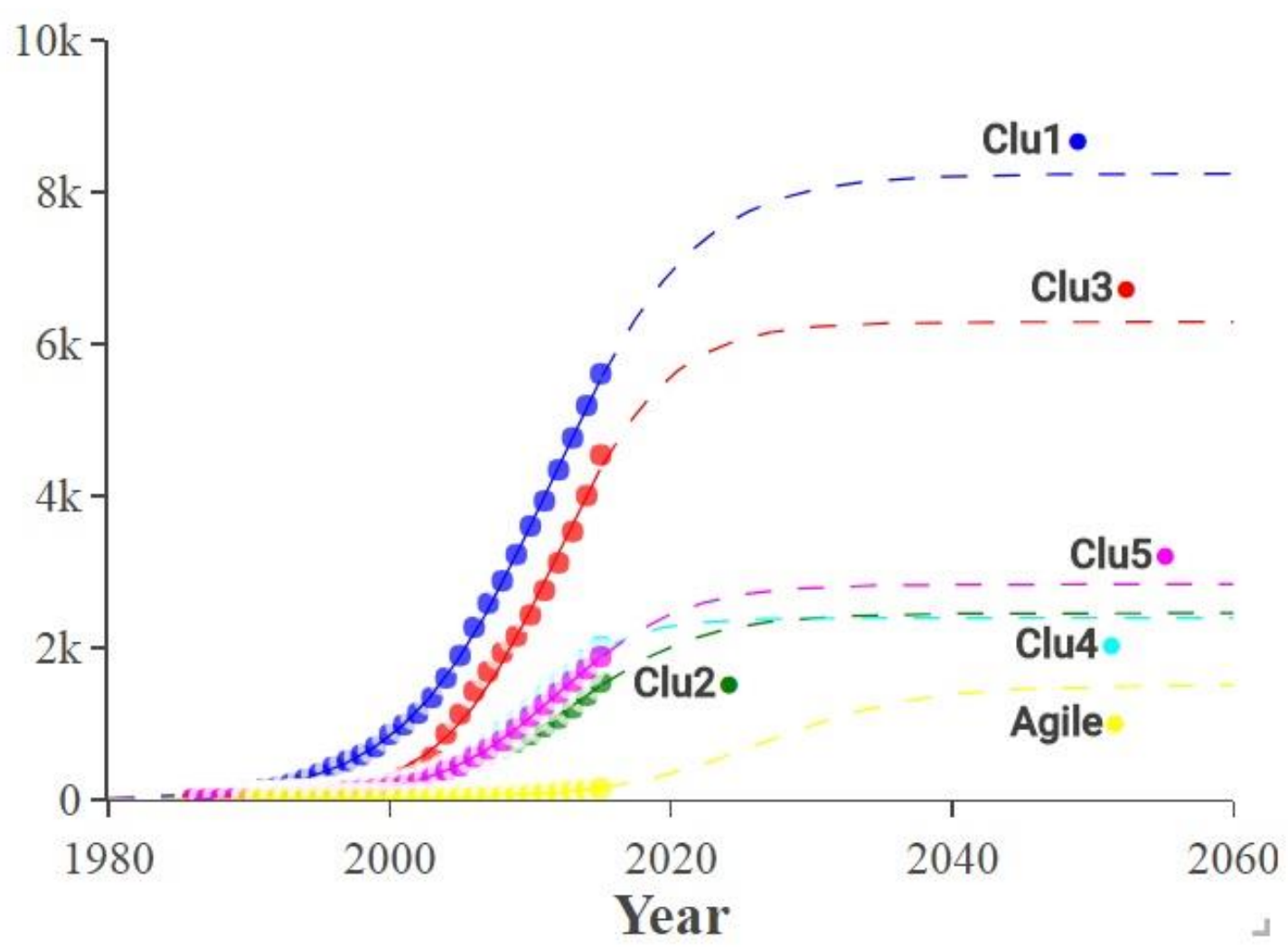

Figure 2: expected trajectory of the overall cumulated number of Scopus-indexed publications concerning each cluster, which is indicated in the illustration through the representative number used throughout the paper, as well as agile-oriented methods in design.

\subsection{Outcomes of the analysis}

With reference to the extracted curves, akin trajectories stand out for the clusters 1 and 3 , as well as for clusters 2, 4 and 5. This remark applies to both the overall intensity of research and the current stages reached by the curves, emphasizing the similitude of patterns. It could be hypothesized that such similar trajectories arise due to low mutual independence of the clusters, or, otherwise said, because of a large number of publications belonging to more clusters. Therefore, the authors have checked the level of overlapping among the clusters, as illustrated in Table 2. The control makes it 
possible to infer that all the cluster document sets share a marginal number of sources with the other ones, although some contents are inherently related, e.g. extraction of customer information (cluster 1) and market data processing (cluster 2). This applies especially to clusters exhibiting similar curves with reference to Figure 2.

Table 2: overlaps between the clusters expressed in percentage terms.

\begin{tabular}{|c|c|c|c|c|c|c|}
\cline { 3 - 7 } \multicolumn{2}{c|}{} & \multicolumn{5}{c|}{ How many publications of the document set below... } \\
\cline { 3 - 7 } \multicolumn{2}{c|}{} & Cluster 1 & Cluster 2 & Cluster 3 & Cluster 4 & Cluster 5 \\
\hline \multirow{3}{*}{$\begin{array}{c}\text {..belong } \\
\text { also to the } \\
\text { document } \\
\text { set on the } \\
\text { right? }\end{array}$} & Cluster 1 & $*$ & $10.0 \%$ & $4.6 \%$ & $4.6 \%$ & $7.3 \%$ \\
\cline { 2 - 7 } & Cluster 2 & $2.8 \%$ & $*$ & $1.1 \%$ & $2.1 \%$ & $1.5 \%$ \\
\cline { 2 - 8 } & Cluster 3 & $3.9 \%$ & $3.1 \%$ & $*$ & $3.7 \%$ & $6.5 \%$ \\
\cline { 2 - 8 } & Cluster 4 & $1.6 \%$ & $2.7 \%$ & $1.6 \%$ & $*$ & $3.4 \%$ \\
\hline
\end{tabular}

At the same time, the variety can be highlighted of aspects, criteria and technologies featuring the clusters, which could follow different and independent patterns. Based on this, the same statistical software applications have been used to check the potential existence of two or more overlapping S-curves in each cluster. However, these results (omitted for the sake of brevity) exhibit a lower goodness of fit than employing a single logistic curve.

Overall, the outcomes and the controls support the correctness of individuating each cluster as a separate dimension in the PP process, each one following its own pattern in terms of research efforts.

\subsection{Considerations about the identified trends}

According to the outcomes presented in the previous section, the following considerations can be drawn. 
- Every cluster is still in its growing phase, as the maturity stage of the curve has not been reached yet. However, the current representative point is just beyond the curve flex representing the highest intensity of research.

- Through a closer analysis of extrapolated data, slight differences can be detected with respect to the expected termination of the S-curves, hence the saturation of the literature production about the corresponding themes. The clusters are expected to include $90 \%$ of the whole number of contributions, as a representative point of obsolescence, between 2018 (cluster 4) and 2024 (cluster

2). To this respect, the clusters will likely include hot topics for no more than 510 years and, thus, we can hypothesize that new topics (characterized by different keywords) are likely to emerge in the meantime.

\section{Potential new trends in early product design phases}

The Introduction Section has already pointed out how design methods introduced in the practice have seldom enjoyed success in the industrial world. This can be seen as practical motivation behind the diminishing interest in some methodological approaches. The tendency towards the expected gradual demise of the contents included in all the five clusters can be considered as a complementary confirmation of hurdles faced by methods and approaches for the FFE.

An exhaustive analysis of the causes of the above issues goes beyond the scopes of the paper, also because these observations radically put into discussion the so-far agreed way of designing. In other terms, some fundamental assumptions, even remarked in the paper, are challenged: from the advantages offered by structured methods to the need to overcome uncertainties in early design stages, from firms' benefitting from the finetuning of products prior to the market launch to the key role played by the FFE in 
determining the future success of designs. For instance, the attempts to manage uncertainties, instead of obtaining knowledge to limit fuzziness, as well as to test deliberately provisional versions of products, characterize agile development. Agile methodologies and approaches based on articulated plans are somehow at the antipodes (Kumar and Tandon, 2017). Agile product development foresees that prototypes are tested in the marketplace and this allows for a continuous acquisition of knowledge (a sort of learning process) with regard to both technical and customer-related aspects (Schuh et al., 2017). This is seen as an advantage over traditional structured and deterministic methods, which are claimed to be too complicated, formalized, irresponsive to new technologies (Grasshiller et al., 2017) and increase time-to-market exceedingly. In addition, the introduction of agile approaches is justified by the supposed impossibility to define products in detail a priori (Böhmer et al., 2017), while Minimum Viable Products (MVPs) are sufficient for exploring the desirability of prospect design outcomes (Keitsch, 2015). At a managerial level, NPD's structuredness and abidance to established procedures are directly challenged by Stage-Gate advocates (Cooper, 2015) with a clear option to include elements of agile strategies (Sommer et al., 2015), which results in a good balance between stability and flexibility of processes (Conforto and Amaral, 2015).

With respect to the above discussion, the authors have subsequently checked the intensity of research concerning agile concepts in design consistently with the previous exploration of the clusters of methods supporting PP, by replicating the investigation approach described in section 5 to the new task. A preliminary list of characterizing terms have been extracted from the keywords of the papers reported in the present section. This has given rise to the definition of the following peculiar keywords (in this case, one occurrence was considered sufficient, as no comprehensive review has been 
conducted): "agile product development", "minimum viable product", "agile project management", "agile development". Still in agreement with the previous bibliographic investigation, the characterizing terms (linked with the OR operator) have been employed in the TAK field for a Scopus document search; the results have been constrained by the presence of one or more terms belonging to the general set in an additional TAK field. The evolution of the research intensity in terms of cumulated number of papers has been likewise calculated. Figure 2 shows the expected trajectory with reference to said evolution (line with yellow dots); data show that $\mathrm{R}^{2}$ is roughly 0.98 and that $90 \%$ of contents will be divulgated within 2039. If the S-curve is compared with those underpinning clustered approaches, it is possible to infer that the obsolescence of agile-related topics might take place about 15 years after an akin demise of topics regarding "traditional" design methods. On the other hand, the overall intensity of research is remarkably lower for agile strategies - to this respect, the smaller number of employed keywords could justify this phenomenon. It is possible to infer that the discussed approaches, which radically challenge established assumptions in engineering design, might represent just a partial contribution to the gradual substitution of "aging" subjects in the NPD domain.

\section{Discussions and conclusions}

\subsection{Summary of findings and outcomes}

The present paper deals with the limited adoption of structured PP methods and attempts to analyse this issue in an original perspective. Indeed, by exploring the intensity of research in field, the paper tries to figure out whether some specific "family" of methods has the potential to become a reference in the future, likely thanks to a successful key to overcome uncertainties and ambiguities. As outlined in the partial conclusions of Section 5, this outcome has not emerged clearly and 
this has urged the authors to explore the phenomenon also in different directions (Section 6). Indeed, the present paper highlights the inability of PP methods to disentangle the complexity of the FFE, at least to such an extent that benefits industrial subjects. This could result in giving up with the objective of introducing structured methodologies in industry and this is supported, but not fully explained, by the current interest in agile approaches. In line with (Ryeong Kim, 2017), a different key of reading might suggest major academic work for fine-tuning PP methods given the variety of functions and attributes that these methods should fulfil; this development should likely foresee crossing the borders of identified clusters and enable the possibility to focus on multiple dimensions consistently. The paper contributes with additional outcomes (listed below), whose utility is discussed in the following subsection together with further comments about the relevance and repercussions of the main findings.

- An original reference framework that classifies the instruments to support PP based on their function or focus.

- $\quad$ An overview of methods capable of supporting PP and distinguished according to the original classification (Section 4).

- A list of keywords (Table 1) that permits to identify methods, instruments and remarkable features ascribable to each cluster.

\subsection{Discussion about the utility of the results}

The findings of the present paper are expectedly relevant for different subjects according to their role in the product development process.

First, organizations can select the most tailored design approaches to PP according to their beliefs about the most meaningful drivers of innovation. This is likely to depend not only on the culture and mission of companies, but also on the industrial domain, 
product maturity, kind of business. The paper claims that the acknowledged distinction between responsive and proactive approaches provides limited support in the selection of appropriate PP tools in terms of said factors. The identification of a suitable methodology based on the responsive vs. proactive distinction might be made in terms of the number of customers available to provide feedback and reveal preferences, as well as their reliability, level of experience, degree of motivation. Of course, these criteria still make sense, although the mechanisms behind NPD are increasingly complex. As well, readers can find both responsive and proactive strategies in all the clusters characterized by the reference innovation focus.

Second, still with a focus on industrial practice, companies might individuate inefficient design activities. Indeed, it can be hypothesized that all the areas covered by clusters (market and customer information, data processing, analysis of external factors and other determinants, human resources, boosting idea generation) are not to be overlooked.

Third, as for academia and the perspective development of new methods, the paper remarks how (at least) five different dimensions should be ideally leveraged and balanced. Still with reference to (projections about) the intensity of research concerning each cluster, all these aspects are expected to be relevant in the near future; hence, disregarding any of them could result in methodological shortcomings. At the same time, despite the value that current design issues still hold, extracted data suggest that we are on the verge of a possible paradigm shift within a decade. This can be seen as the consequence of the difficulties in implementing "systematic" approaches, which often require not negligible efforts for their integration in firms' product development cycles. The present analysis does not individuate which unprecedented foci are expected to play a major role in the upcoming years, although some signals emerge about the interest in 
embracing agile strategies in design. Indeed, the trend of the interpolated data related to the literature contributions focused on the "agile" concept suggests margins of growth that result more enduring than the ones related to the clustered topics. As already pointed out, the possible large-scale adoption of agile approaches might have a tremendous impact on design practices. Here, the product is continuously redesigned and updated and the FFE is no longer a real "front end", but it becomes a key element of an iterative approach to customer discovery and further product development. Since agile and lean approaches seem to be more tailored to industry needs, at least in the

current time period, future research might consider the chance to support the potential transition towards these approaches and the creation of appropriate frameworks that allow designers to fully exploit their potential.

\subsection{Limitations and future work}

As discussed in Section 5, the independence of the S-curves associated with clusters supports the robustness of the distinction between clusters featured by different foci. However, some methodological limitations have to be underlined, as they can bias outcomes.

The selection of design tools (and corresponding scientific material) included in each cluster has been performed subjectively. Besides, some instruments and techniques have been undoubtedly introduced that swivel on more foci, as well as some peculiar objectives can be seen as common traits of more clusters. This can motivate the overlap between cluster document sets, although limited. The identification of relevant keywords based on the selected literature introduced another element of subjectivity, although the criteria to individuate these terms have been already clarified. This course of action has resulted in an unbalanced number of keywords referable to the different 
clusters. A more balanced distribution could not be predetermined, but this is a possible reason behind the very different volume of literature ascribable to each cluster. In addition, the document sets do not strictly correspond with samples of contributions that contribute to enhance design according to the foci of the clusters. Given the large number of gathered papers, a manual selection of impacting contributions was considered extremely time-consuming, as well as it would have introduced further subjectivity.

In the perspective of individuating trends, insightful information could be obtained by analysing patterns of citation and co-citation across clusters. Such an investigation might also contribute to a major understanding in the way achievements in certain areas affect advances in other clusters. For instance, the creative dimension and the way creativity is supported might be critical for approaches focusing on open innovation, but this supposed impact should be verified appropriately.

Said citation analysis represents a planned future activity, together with experiments aimed at verifying the effectiveness of the clusters as a means to support the selection of design strategies in the practice.

\section{References}

Achiche, S., Appio, F. P., McAloone, T. C., \& Di Minin, A. (2013). Fuzzy decision support for tools selection in the core front end activities of new product development. Research in engineering design, 24(1), 1-18.

Agouridas, V., McKay, A., Winand, H., \& de Pennington, A. (2008). Advanced product planning: a comprehensive process for systemic definition of new product requirements. Requirements Engineering, 13(1), 19-48.

Aiken, M., Krosp, J., Shirani, A., \& Martin, J. (1994). Electronic brainstorming in small and large groups. Information \& Management, 27(3), 141-149.

Altshuller, G. S. (1984). Creativity as an exact science. Gordon and Breach. 
Annarelli, A., Battistella, C., \& Nonino, F. (2016). Product service system: A conceptual framework from a systematic review. Journal of Cleaner Production, 139, 1011-1032.

Aschehoug, S. H., \& Boks, C. (2011). Success criteria for implementing sustainability information in product development. In DS 68-5: Proceedings of the 18th International Conference on Engineering Design (ICED 11), Impacting Society through Engineering Design, Vol. 5: Design for X/Design to X, Lyngby/Copenhagen, Denmark, 15-19 August 2011.

Aschehoug, S. H., \& Ringen, G. (2013). Open innovation and idea generation in SMEs. In DS 75-1: Proceedings of the 19th International Conference on Engineering Design (ICED13), Design for Harmonies, Vol. 1: Design Processes, Seoul, Korea, 19-22 August 2013.

Aspara J, Hietanen J, Parvinen P, Tikkanen H (2008) An exploratory empirical verification of Blue Ocean Strategies: findings from Sales Strategy. 8th International Business Research Conference, IBR 2008, Dubai, United Arab Emirates, 27-28 March 2008.

Atuahene-Gima, K., Slater, S. F., \& Olson, E. M. (2005). The contingent value of responsive and proactive market orientations for new product program performance. Journal of product innovation management, 22(6), 464-482.

Bacciotti, D., Borgianni, Y., \& Rotini, F. (2013). Overview of methods supporting product planning: Open research issues. In DS 75-1: Proceedings of the 19th International Conference on Engineering Design (ICED13), Design for Harmonies, Vol. 1: Design Processes, Seoul, Korea, 19-22 August 2013.

Bacciotti, D., Borgianni, Y., \& Rotini, F. (2016b). An original design approach for stimulating the ideation of new product features. Computers in Industry, 75, 80100.

Bacciotti, D., Borgianni, Y., Cascini, G., \& Rotini, F. (2016a). Product Planning techniques: investigating the differences between research trajectories and industry expectations. Research in Engineering Design, 27(4):367-389.

Blessing, L. (2003). What is this thing called design research?. In DS 31: Proceedings of the 14th International Conference on Engineering Design, Stockholm, Sweden, 19-21 August 2003.

Böhmer, A. I., Hostettler, R., Richter, C., Lindemann, U., Conradt, J., \& Knoll, A. (2017). Towards Agile Product Development-The Role of Prototyping. In DS 
87-4 Proceedings of the 21st International Conference on Engineering Design (ICED 17) Vol 4: Design Methods and Tools, Vancouver, Canada, 21-25.08. 2017.

Borgianni, Y., \& Matt, D. T. (2016). Ideality in Axiomatic Design and beyond. Procedia CIRP, 53, 95-100.

Borgianni, Y., Cardillo, A., Cascini, G., \& Rotini, F. (2011). Systematizing new value proposition through a TRIZ-based classification of functional features. Procedia Engineering, 9, 103-118.

Bovea, M., \& Pérez-Belis, V. (2012). A taxonomy of ecodesign tools for integrating environmental requirements into the product design process. Journal of Cleaner Production, 20(1), 61-71.

Bruneel, J., d'Este, P., \& Salter, A. (2010). Investigating the factors that diminish the barriers to university-industry collaboration. Research Policy,39(7), 858-868.

Bullinger, H. J., Bauer, W., Wenzel, G., \& Blach, R. (2010). Towards user centred design (UCD) in architecture based on immersive virtual environments. Computers in Industry, 61(4), 372-379.

Büyüközkan, G., \& Feyzioğlu, O. (2004). A new approach based on soft computing to accelerate the selection of new product ideas. Computers in Industry, 54(2), 151167.

Cantamessa, M., Montagna, F., \& Cascini, G. (2016). Design for innovation-A methodology to engineer the innovation diffusion into the development process. Computers in Industry, 75, 46-57.

Chakrabarti, A. (2006). Defining and supporting design creativity. In DS 36: Proceedings of DESIGN 2006, the 9th International Design Conference, Dubrovnik, Croatia., 15-18 May 2006.

Chen, C. H., Khoo, L. P., \& Yan, W. (2003). Evaluation of multicultural factors from elicited customer requirements for new product development. Research in Engineering Design, 14(3), 119-130.

Chesbrough, H., \& Schwartz, K. (2007). Innovating business models with codevelopment partnerships. Research-Technology Management, 50(1), 55-59.

Chulvi, V., González-Cruz, M. C., Mulet, E., \& Aguilar-Zambrano, J. (2013). Influence of the type of idea-generation method on the creativity of solutions. Research in Engineering Design, 24(1), 33-41. 
Coates, N. F., Cook, I., \& Robinson, H. (1997). Idea generation techniques in an industrial market. Journal of Marketing Practice: Applied Marketing Science, 3(2), 107-118.

Conforto, E. C., \& Amaral, D. C. (2016). Agile project management and stage-gate model-A hybrid framework for technology-based companies. Journal of Engineering and Technology Management, 40, 1-14.

Cooper, R. G. (2014). What's Next?: After Stage-Gate. Research-Technology Management, 57(1), 20-31.

Daim, T. U., Rueda, G., Martin, H., \& Gerdsri, P. (2006). Forecasting emerging technologies: Use of bibliometrics and patent analysis. Technological Forecasting and Social Change, 73(8), 981-1012.

D'Anna, W., \& Cascini, G. (2016). Adding quality of life to design for Eco-Efficiency. Journal of Cleaner Production, 112, 3211-3221.

De Bono E (1968) New think: the use of lateral thinking in the generation of new ideas. Basic Books, New York

De Bono E (2009) Six Thinking Hats, 2nd edition. Penguin, London

De Bono, E. (1994). Creativity and quality. Quality Management in Healthcare, 2(3), 14.

De Couvreur, L., \& Goossens, R. (2011). Design for (every) one: co-creation as a bridge between universal design and rehabilitation engineering. CoDesign, 7(2), 107-121.

De Lessio, M. P., Wynn, D. C., \& Clarkson, P. J. (2017). Modelling the planning system in design and development. Research in Engineering Design, in press.

Dewulf, K. (2013). Sustainable product innovation: the importance of the front-end stage in the innovation process. In Advances in industrial design engineering. Intech.

Duarte, R., Mesnard, M., \& Nadeau, J. P. (2017). An innovative design approach to develop external articular medical devices. International Journal on Interactive Design and Manufacturing (IJIDeM), 11(2), 375-383.

Efimenko, I. V., \& Khoroshevsky, V. F. (2017). Peaks, Slopes, Canyons and Plateaus: Identifying Technology Trends Throughout the Life Cycle. International Journal of Innovation and Technology Management, 14(02), 1740012. 
Ericson, Å., Larsson, T., Larsson, A., \& Larsson, M. (2007). Need driven product development in team-based projects. In Proceedings of the 14th International Conference on Engineering Design, Paris, France, 28-31 August 2007

Ericson, A., Müller, P., Larsson, T. C., \& Stark, R. (2009). Product-service systemsfrom customer needs to requirements in early development phases. In Proceedings of the 1st CIRP industrial product-service systems (IPS2) conference. Cranfield, UK, 1-2 April 2009.

Flint, D. J. (2002). Compressing new product success-to-success cycle time: Deep customer value understanding and idea generation. Industrial marketing management, 31(4), 305-315.

Fiorineschi, L., Frillici, F.S., \& Rotini, F. (2018). Enhancing Functional Decomposition and Morphology with TRIZ: A Literature Review. Computers in Industry, 94 (January), 1-15.

Frey, D., Palladino, J., Sullivan, J., \& Atherton, M. (2007). Part count and design of robust systems. Systems engineering, 10(3), 203-221.

Füller, J., \& Matzler, K. (2007) Virtual product experience and customer participationA chance for customer-centred, really new products. Technovation 27(6):378387.

Gero, J. S., Jiang, H., \& Williams, C. B. (2013). Design cognition differences when using unstructured, partially structured, and structured concept generation creativity techniques. International Journal of Design Creativity and Innovation, 1(4), 196-214.

Glavič, P., \& Lukman, R. (2007). Review of sustainability terms and their definitions. Journal of cleaner production, 15(18), 1875-1885.

Graner, M., \& Mißler-Behr, M. (2012). The use of methods in new product development-a review of empirical literature. International Journal of Product Development, 16(2), 158-184.

Grashiller, M., Luedeke, T., \& Vielhaber, M. (2017). Integrated approach to the agile development with design thinking in an industrial environment. In DS 87-2 Proceedings of the 21st International Conference on Engineering Design (ICED 17) Vol 2: Design Processes, Design Organisation and Management, Vancouver, Canada, 21-25.08. 2017.

Hartono M, Chuan TK, Peacock JB (2012) Cultural differences in applying Kansei Engineering to services. IEEE Southeast Asian Network of Ergonomics 
Societies Conference, SEANES 2012, Langkawi, Malaysia, 9-12 July 2012, pp $1-5$

Hatcher, G., Ion, W., Maclachlan, R., Wodehouse, A., Sheridan, M., \& Simpson, B. (2016). Humour processes for creative engineering design. In DS 84:

Proceedings of the DESIGN 2016 14th International Design Conference, Dubrovnik, Croatia, 16-19 May 2016.

Howard, T. J., Culley, S., \& Dekoninck, E. A. (2011). Reuse of ideas and concepts for creative stimuli in engineering design. Journal of Engineering Design, 22(8), $565-581$.

Hüsig, S., \& Kohn, S. (2009). Computer aided innovation-State of the art from a new product development perspective. Computers in Industry, 60(8), 551-562.

Jowers, I., Prats, M., McKay, A., \& Garner, S. (2013). Evaluating an eye tracking interface for a two-dimensional sketch editor. Computer-Aided Design, 45(5), 923-936.

Kano, N., Seraku, N., Takahashi, F., \& Tsuji, S. (1984). Attractive quality and must-be quality. Journal of the Japanese Society for Quality Control 14(2):39-48.

Kaplan, S., \& Tripsas, M. (2008). Thinking about technology: Applying a cognitive lens to technical change. Research Policy, 37(5):790-805.

Kärkkäinen, H., \& Elfvengren, K. (2002). Role of careful customer need assessment in product innovation management-empirical analysis. International Journal of Production Economics, 80(1):85-103.

Keitsch, M. M. (2015). Design Driven Innovation-Minimum Viable Products for local entrepreneurship in Nepal. In DS 80-8 Proceedings of the 20th International Conference on Engineering Design (ICED 15) Vol 8: Innovation and Creativity, Milan, Italy, 27-30 July 2015.

Keitsch, M. M. (2015). Design driven innovation-Minimum Viable Products for local entrepreneurship in Nepal. In DS 80-8 Proceedings of the 20th International Conference on Engineering Design (ICED 15) Vol 8: Innovation and Creativity, Milan, Italy, 27-30.07. 15.

Khushaba, R. N., Wise, C., Kodagoda, S., Louviere, J., Kahn, B. E., \& Townsend, C. (2013). Consumer neuroscience: Assessing the brain response to marketing stimuli using electroencephalogram (EEG) and eye tracking. Expert Systems with Applications, 40(9), 3803-3812. 
Kim W.C., \& Mauborgne, R. (2005). Blue Ocean Strategy. Harvard Business School Press, Cambridge

Klein, A., \& Spiegel, G. (2013). Social media in the product development process of the automotive industry: a new approach. In: Kurosu M. (ed) Human-Computer Interaction: Users and Contexts of Use. Springer Berlin Heidelberg, pp. 396-401

Kotler, P. (2007). Marketing Management, 12th edition. Prentice Hall, Englewood Cliffs

Kumar Patra, S., \& Chand, P. (2005). Biotechnology research profile of India. Scientometrics, 63(3), 583-597.

Kumar, P., \& Tandon, P. (2017). Classification and mitigation of uncertainty as per the product design stages: framework and case study. Journal of the Brazilian Society of Mechanical Sciences and Engineering, 39(11), 4785-4806.

Liao, S. H., Hsieh, C. L., \& Huang, S. P. (2008). Mining product maps for new product development. Expert Systems with Applications, 34(1), 50-62.

Liberatore, M. J., \& Stylianou, A. C. (1995). toward a framework for developing knowledge-based decision support systems for customer satisfaction assessment: An application in new product development. Expert Systems with Applications, 8(1), 213-228.

Lilien, G. L., Morrison, P. D., Searls, K., Sonnack, M., \& Von Hippel, E. (2002). Performance assessment of the lead user idea-generation process for new product development. Management science, 48(8), 1042-1059.

Lindič, J., Bavdaž, M., \& Kovačič, H. (2012). Higher growth through the Blue Ocean Strategy: Implications for economic policy. Research policy, 41(5), 928-938.

Liu, Y., Jin, J., Ji, P., Harding, J. A., \& Fung, R. Y. (2013). Identifying helpful online reviews: a product designer's perspective. Computer-Aided Design, 45(2), 180194.

Lohmeyer, Q., \& Meboldt, M. (2016). The Integration of Quantitative Biometric Measures and Experimental Design Research. In Experimental Design Research, Springer International Publishing, pp. 97-112.

López-Mesa, B., \& Bylund, N. (2011). A study of the use of concept selection methods from inside a company. Research in Engineering Design, 22(1), 7-27.

Lu, L. Y., \& Liu, J. S. (2013). An innovative approach to identify the knowledge diffusion path: the case of resource-based theory. Scientometrics, 94(1), 225246. 
Matsatsinis, N. F., \& Siskos, Y. (1999). MARKEX: An intelligent decision support system for product development decisions. European Journal of Operational Research, 113(2), 336-354.

Matthews, B. (2009). Intersections of brainstorming rules and social order. CoDesign, $5(1), 65-76$.

Milekic, S. (2012) Using eye- and gaze-tracking to interact with a visual display. In S. Dunn, J. Bowen and K. Ng (eds.): Proceedings of EVA London 2012, London 10-12 July 2012.

Moon, S. E., Kim, J. H., Kim, S. W., \& Lee, J. S. (2017, May). Assessing Product Design Using Photos and Real Products. In Proceedings of the 2017 CHI Conference Extended Abstracts on Human Factors in Computing Systems (pp. 1100-1107). ACM.

Mussgnug, M., Singer, D., Lohmeyer, Q., \& Meboldt, M. (2017). Automated interpretation of eye-hand coordination in mobile eye tracking recordings. KIKünstliche Intelligenz, 31(4), 331-337.

Mussgnug, M., Waldern, M. F., \& Meboldt, M. (2015). Mobile eye tracking in usability testing: designers analysing the user-product interaction. In DS 80-2 Proceedings of the 20th International Conference on Engineering Design (ICED 15) Vol 2: Design Theory and Research Methodology Design Processes, Milan, Italy, 27-30.07. 15.

Nagamachi, M. (1995). Kansei engineering: a new ergonomic consumer-oriented technology for product development. International Journal of industrial ergonomics, 15(1), 3-11.

Narver, J. C., Slater, S. F., \& MacLachlan, D. L. (2004). Responsive and proactive market orientation and new-product success. Journal of product innovation management, 21(5), 334-347.

Osborn AF (1953) Applied Imagination. Scribner: Oxford

Oulasvirta, A., Kurvinen, E., \& Kankainen, T. (2003). Understanding contexts by being there: case studies in bodystorming. Personal and ubiquitous computing, 7(2), 125-134.

Oztekin, A., Iseri, A., Zaim, S., \& Nikov, A. (2013). A Taguchi-based Kansei engineering study of mobile phones at product design stage. Production Planning \& Control, 24(6), 465-474. 
Pahl G, Beitz W, Feldhusen J, Grote KH (2007) Engineering design: a systematic approach. Springer, London

Pavković, N., Štorga, M., Bojčetić, N., \& Marjanović, D. (2013). Facilitating design communication through engineering information traceability. Artificial Intelligence for Engineering Design, Analysis and Manufacturing, 27(02), 105119.

Qu, M., Yu, S., Chen, D., Chu, J., \& Tian, B. (2016). State-of-the-art of design, evaluation, and operation methodologies in product service systems. Computers in Industry, 77, 1-14.

Ramaswamy, R., \& Ulrich, K. (1993). Augmenting the house of quality with engineering models. Research in Engineering Design, 5(2), 70-79.

Rietzschel, E. F., Nijstad, B. A., \& Stroebe, W. (2006). Productivity is not enough: A comparison of interactive and nominal brainstorming groups on idea generation and selection. Journal of Experimental Social Psychology, 42(2), 244-251.

Ryeong Kim, S. (2017). Idea Management. Identifying the factors that contribute to uncertainty in idea generation practices within front end NPD. The Design Journal, 20(sup1), S4398-S4408.

Sakao, T., \& Shimomura, Y. (2007). Service Engineering: a novel engineering discipline for producers to increase value combining service and product. Journal of Cleaner Production, 15(6), 590-604.

Schaffhausen, C. R., \& Kowalewski, T. M. (2015). Large-Scale Needfinding: Methods of Increasing User-Generated Needs From Large Populations. Journal of Mechanical Design, 137(7), 071403.

Schuh, G., Gartzen, T., Soucy-Bouchard, S., \& Basse, F. (2017). Enabling agility in product development through an adaptive engineering change management. Procedia CIRP, 63, 342-347.

Schütte, S. T., Eklund, J., Axelsson, J. R., \& Nagamachi, M. (2004). Concepts, methods and tools in Kansei engineering. Theoretical Issues in Ergonomics Science, 5(3), 214-231.

Simonton, D. K. (2003). Scientific creativity as constrained stochastic behavior: the integration of product, person, and process perspectives. Psychological bulletin, $129(4), 475$.

Sommer, A. F., Hedegaard, C., Dukovska-Popovska, I., \& Steger-Jensen, K. (2015). Improved product development performance through Agile/Stage-Gate hybrids: 
The next-generation Stage-Gate process?. Research-Technology Management, 58(1), 34-45.

Soukhoroukova, A., Spann, M., \& Skiera, B. (2012). Sourcing, filtering, and evaluating new product ideas: An empirical exploration of the performance of idea markets. Journal of Product Innovation Management, 29(1), 100-112.

Stempfle, J., \& Badke-Schaub, P. (2002). Thinking in design teams-an analysis of team communication. Design studies, 23(5), 473-496.

Suarez, F. F., \& Utterback, J. M. (1995). Dominant designs and the survival of firms. Strategic management journal, 16(6), 415-430.

Suri, J. F., \& Marsh, M. (2000). Scenario building as an ergonomics method in consumer product design. Applied ergonomics, 31(2), 151-157.

Toubia, O. (2006). Idea generation, creativity, and incentives. Marketing Science, 25(5), 411-425.

Tsai, K. H., Chou, C., \& Kuo, J. H. (2008). The curvilinear relationships between responsive and proactive market orientations and new product performance: A contingent link. Industrial Marketing Management, 37(8), 884-894.

Tukker, A., \& Tischner, U. (2006). Product-services as a research field: past, present and future. Reflections from a decade of research. Journal of cleaner production, 14(17), 1552-1556.

Tyl, B., Legardeur, J., Millet, D., \& Vallet, F. (2014). A comparative study of ideation mechanisms used in eco-innovation tools. Journal of Engineering Design, 25(1012), 325-345.

Tzortzopoulos, P., Cooper, R., Chan, P., \& Kagioglou, M. (2006). Clients' activities at the design front-end. Design Studies, 27(6), 657-683.

Vernon, D., \& Hocking, I. (2016). Beyond belief: Structured techniques prove more effective than a placebo intervention in a problem construction task. Thinking Skills and Creativity, 19, 153-159.

Von Hippel E (2005) Democratizion innovation. The MIT Press, Cambridge

Von Hippel, E. (1986). Lead users: a source of novel product concepts. Management science, 32(7), 791-805.

von Saucken, C., Guertler, M., Schneider, M., \& Lindemann, U. (2015). A method model for distinguishing and selecting open innovation methods. In DS 80-8 Proceedings of the 20th International Conference on Engineering Design (ICED 15) Vol 8: Innovation and Creativity, Milan, Italy, 27-30 July 2015. 
Wang, K. C. (2011). A hybrid Kansei engineering design expert system based on grey system theory and support vector regression. Expert Systems with Applications, 38(7), 8738-8750.

Wassenaar, H. J., Chen, W., Cheng, J., \& Sudjianto, A. (2005). Enhancing discrete choice demand modeling for decision-based design. Journal of Mechanical Design, 127(4), 514-523.

Whyte, J. K., Davies, A., Salter, A. J., \& Gann, D. M. (2003). Designing to compete: lessons from Millennium Product winners. Design Studies, 24(5), 395-409.

Witell, L., Löfgren, M., \& Dahlgaard, J. J. (2013). Theory of attractive quality and the Kano methodology-the past, the present, and the future. Total Quality Management \& Business Excellence, 24(11-12), 1241-1252.

Wodehouse, A., Maclachlan, R., \& Gray, J. (2014). The best form of medicine? Using humor to enhance design creativity. International Journal of Design Creativity and Innovation, 2(3), 125-141.

Woolley, A., Loudon, G., Gill, S., \& Hare, J. (2013). Getting into Context Early: A Comparative Study of Laboratory and In-Context User Testing of Low-Fidelity Information Appliance Prototypes. The Design Journal, 16(4), 460-485.

Yang, C. C. (2005). The refined Kano's model and its application. Total Quality Management \& Business Excellence, 16(10), 1127-1137.

Yang, C. C. (2011). Constructing a hybrid Kansei engineering system based on multiple affective responses: Application to product form design. Computers \& Industrial Engineering, 60(4), 760-768.

Yilmaz, S., Daly, S. R., Seifert, C. M., \& Gonzalez, R. (2016). Evidence-based design heuristics for idea generation. Design Studies, 46, 95-124.

Yoshimura, M. (2012). Framework and methodologies for maximising achievements of product designs by collaborative works. Journal of Engineering Design, 23(9), 674-695

Zahedi, M., \& Guité, M. (2013). Introducing nature analogies at the framing stage of design projects. In DS 76: Proceedings of E\&PDE 2013, the 15th International Conference on Engineering and Product Design Education, Dublin, Ireland, 0506 September 2013.

Zhai, L. Y., Khoo, L. P., \& Zhong, Z. W. (2009). A dominance-based rough set approach to Kansei Engineering in product development. Expert Systems with Applications, 36(1), 393-402. 